OPEN

SUBJECT AREAS:

CANCER SCREENING

PREVENTIVE MEDICINE

ECONOMICS

POPULATION SCREENING

Received

5 March 2013

Accepted

8 July 2013

Published

6 August 2013

Correspondence and requests for materials should be addressed to A.L. (alabeit. publications@gmail. com)

\title{
Cervical Cancer Screening Service Utilisation in UK
}

\author{
Alexander Labeit ${ }^{1}$, Frank Peinemann ${ }^{2} \&$ Abbi Kedir $^{3}$
} 'Department of Health Sciences, University of Leicester, Leicester, LE 1 6TP, UK, ${ }^{2}$ FOM University of Applied Science for Economics \&
Management, 45141 Essen, Germany, ${ }^{3}$ Department of Economics, University of Leicester, Leicester, LE1 7RH, UK.

This study investigates empirically how past screening behaviour, individual and household characteristics affect the current uptake of cervical cancer screening in UK. For the conceptual framework, we use a modified Grossman model which is extended for non-economic factors. A dynamic version of a random effects panel probit model with initial conditions is estimated on the balanced sub-sample of the data. The analysis sample is restricted to women of age 16 and older and grouped into different age categories with respect to the NHS Cervical Screening Programme (NHSCSP). As dataset a balanced panel data of 857 women with 11,998 observations from the British Household Panel Study (BHPS) for the period from 1992 to 2008 is used for the analysis. Results suggest show that previous screening uptake, age, partner status, employment status and a previous GP visit have a significant influence on the likelihood of the uptake of cervical cancer screening.

eduction of health care costs is one of the priorities for NHS in UK in consideration of tight government budgets. Prevention is especially important in this context, because health check-ups and screening exams which are offered by NHS in UK lead to an early detection of diseases. Cervical cancer screening is a typical example of secondary prevention. Cervical cancer screening has been estimated to cost around $£ 175$ million a year in England which includes the cost of treating cervical abnormalities ${ }^{1}$. Primary Care Trusts (PCTs) are also responsible for the commissioning of cervical screening from the overall allocation they receive from the Department of Health.

In contrast to some other types of cancer cervical cancer can normally be effectively treated if it is detected at an early stage and for women with a diagnosis of cervical cancer curative treatment exist with an excellent survival prognosis ${ }^{2}$. Survival figures for England show that around 67 per cent of women diagnosed with cervical cancer between 2005 and 2009 were alive five years later ${ }^{3}$. Cervical cancer screening is considered as a good protection against cervical cancer, because of the early detection of this cancer type and many women who develop cervical cancer have never been screened ${ }^{4}$. It is estimated that up to $92 \%$ dying from cervical cancer has never been tested. In 2008, there have been 2250 new registrations of invasive cervical cancer ${ }^{3}$ and 830 women died from cervical cancer in England ${ }^{5}$. It is estimated that cervical cancer screening prevents about 4,500 cases of cervical cancer per year in the $\mathrm{UK}^{6}$.

Cervical cancer screening started in Britain in the mid-1960s ${ }^{7}$. By the mid-1980s, although many women were having regular smear tests, there was concern that those women at greatest risk were not being tested, and that those who had positive results were not being followed up and treated effectively. Because of these reasons the NHS Cervical Screening Programme (NHSCSP) was set up in 1988 when the Department of Health instructed all health authorities to introduce computerised call-recall systems and to meet certain quality standards ${ }^{6}$. This programme has invited about 4.5 million women for screening in 2010/11 and 3.4 million women screened in 2010/11 in England ${ }^{8}$. Most women in the target age group were tested following an invitation and the rest were screened opportunistically at the suggestion of the sample taker or of the woman herself ${ }^{1}$. Invitation by the woman is done by the NHS call and recall system which invites women who are registered with a GP. It also keeps track of any follow-up investigation and recalls the woman for screening in three or five years' time if there is no abnormality. It is therefore important that all women ensure their GP has their correct name and address details and inform them if address details change if there has been a change of residence.

Within the NHS Cervical Screening Programme women should receive now their first invitation for routine screening at 25. In October 2003 there has been a change in national policy for starting age of cervical cancer screening age which has been raised from age 20 to 25 . There was a discussion to lower the starting age again to 20 in England ${ }^{9}$, however the Advisory committee on cervical screening (ACCS) reviewed the policy of starting screening at age 25 and agreed not to change the current screening policy in England ${ }^{10}$. The policy of starting 
screening is different in Scotland and Wales, because cervical cancer screening starts from age $20^{11,12}$. The NHS Cervical Screening offers screening at different intervals depending on age and is free of charge. The intervals for screening are: age 20 or 25 first invitation, age 20 or 25-49 3 yearly period since 2003 (changing from a 5 yearly period before 2003), age 50-64 5 yearly period, age $65+$ screening only for those women who have not been screened since age 50 or who have had recent abnormal tests. Women aged 65 and over are taken out of the call recall (invitation) system unless they need ongoing surveillance or follow up. This is considered as necessary if a woman has had an abnormal result in any of her three most recent tests. Women aged 65 and over who have never had a test are entitled to one. Although the cervical screening programme is a national programme, there is considerable variation in the local implementation of the national guidance and the invitation by the recall system for cervical screening can differ from the national recommendation $^{13}$. This is shown by the fact that $85 \%$ of Primary Care Trusts have invited women for a cervical cancer screening every 3 years and $15 \%$ have had a mixed policy of inviting every 3 or 5 years depending on the age of women until $2002^{14}$.

The success of the NHS Cervical Screening Programme can be seen by decreasing incidence and mortality rates. First, cervical cancer incidence rates have dropped considerably after the NHS Cervical Screening Programme started in the UK in the late 1980s. In UK, the age-standardised incidence rate almost halved from 16 per 100,000 women in $1986-1988$ to 8.5 per 100,000 women in $2006-2008^{1}$ and the number of new cases decreased about $35 \%$ compared to the $1980 \mathrm{~s}^{6}$. Second, the success of cervical cancer screening can be seen second by the fact that mortality rates in 2008 are nearly 70 per cent lower (2.4 per 100,000 females) than they were 30 years earlier (7.1 per 100,000 females in 1979) ${ }^{1}$. A relevant number for judging the effectiveness of this programme is the coverage rate which measures the percentage of women in the relevant age group from 25 to 64 who have been screened in the last five years. There has been an increase from $61 \%$ in $1992 / 93$ to $80 \%$ in $2005^{15}$ and since then there has been a slight decrease of the coverage rate in the last years: it has been fallen to $78.6 \%$ in $2010 / 11^{16,17}$. Comparing coverage rates between 1995 and 2005 there has been a slight increase for women above 55 and a decrease for women younger than 34 . The purpose of our paper is to develop a conceptual theoretical framework for analysing cervical screening uptake and to conduct an empirical analysis controlling for a large number of individual and household characteristics and to give policy recommendations.

\section{Results}

Economic models of preventative health care use. Economic models for the demand of health care are based on human capital models and in these models the demand for health goods are derived from the generic demand for health ${ }^{18}$. This general framework has also been adopted for the modelling of the demand for preventative care and also for the special case of cancer prevention ${ }^{19}$. Cervical cancer screening falls within the category of secondary prevention and acts as self-protection measure which enhances the early detection probability and reduces the consequences of ill health ${ }^{20}$. However, two important aspects which are relevant for the demand of preventative care are typically not considered at the same time in detail in models for demand of health care: distinction between acute and preventative care and uncertainty. Some dynamic economic models for the demand of health care incorporates uncertainty, but makes no distinction between acute and preventative care ${ }^{21}$. Acute care represents especially the consumption aspect of health whereas preventative care (i.e. screening services) represents the investment aspect. Other economic models such as the simplified Grossman model makes the distinction between acute and preventative care, but include no uncertainty ${ }^{22}$. Only one economic model considers explicitly the demand for preventative health care and uncertainty in a stochastic dynamic framework ${ }^{23}$, however does not consider non-economic factors.

Therefore, our conceptual framework for the uptake of cervical cancer screening care is based on a human capital approach ${ }^{23}$, however it includes further non-economic factors such as non-monetary barriers. This approach is also supported by previous research which has investigated determinants of screening uptake in general and female specific cancer screening such as breast and cervical screening in particular ${ }^{24}$. Uptake of screening exams such as pap smears was not only affected by direct and indirect costs of the screening exams, but also by a wide range of individual, family characteristics and other conditions such as attitudes, beliefs, barriers and facilitating conditions.

Hypotheses. Age can have different effects on the demand for using health care and also for the demand of prevention. In the Grossmann model health depreciates with an increasing rate at older ages and so the health stock falls with increased necessity and demand for prevention activities. This matches also with the fact, that middle aged women have a higher risk of developing cervical cancer. Median age at diagnosis for cervical cancer is in the late $40 \mathrm{~s}$ and benefits of screening with avoiding cervical cancer cases has been shown most useful for women between their $40 \mathrm{~s}$ and late $60 \mathrm{~s}^{10}$. Higher perceived risk could lead to an increased use of preventive care due to increased risks of developing cervical cancer in middle age. However, older individuals have also a shorter pay-off period and returns of preventions activities would be reduced. The resulting effect of increasing age is unclear and because of nonlinearities age is modelled in different age categories starting with age 16-24 as reference group. Empirical studies find often a negative relationship between age and uptake of cervical and breast cancer screening ${ }^{25,26}$. Education increases the uptake of preventative care for several reasons, because better educated individuals have a higher efficiency in the production of health. There are possible further transmission channels for effect of education on uptake such as increased self-efficacy, confidence, motivation, patience and social inclusion ${ }^{27}$. Schooling will be used as a proxy for education with primary education (ISCED classification) as reference category and secondary and tertiary education as further education levels. Females with partners will be more likely to participate in prevention activities, because partners will take care for each other and women will show risk-adverse behaviour ${ }^{28,29}$. Number and age of children could influence uptake through time constraints, especially small children may reduce women's availability of time for a cervical cancer screening ${ }^{30}$. For the children two variables will be used: total number of children living in the household and number of children under the age of 4 . Household income could have possible different effects on screening uptake. On one hand it is predicted to have a positive impact on screening uptake, because higher income leads to an increase in demand for time in perfect health, however on the other hand higher income which is induced by a higher salary increases leisure cost and time cost for prevention activities. However, there is empirically support that increasing income leads to higher demand for preventive health care $^{26,31,32}$. Household income should have a lower effect on uptake on preventative services in UK than in other countries, because access to health care and most of the preventative services is free in UK. Household income was deflated and transformed in per capita income using the modified OECD scale to allow for household size and needs ${ }^{33}$. Employment status has been shown to be correlated with the uptake of cervical screening and employed women have a higher uptake of cervical cancer screening and in some studies it was a stronger predictor of non-attendance than income and education $^{28,29}$. The GP plays a prominent role in the UK health care system as a gate keeper and this is also the case for the 
demand of preventative health care, because the GP is the first point of contact for every non-urgent medical condition and before visiting a medical specialist ${ }^{34}$. In countries with a centralized health system such with the NHS in the UK the GP is in an important place to inform the patient about the relevance of prevention and this is also the case for cervical cancer screening. A higher number of GP visits should lead to a higher uptake of cervical cancer screening. Self-rated health status of the individuals can either have a positive or negative impact on the probability of screening. On one hand, individuals in a poor health status will try to increase their stock of health and so demand for preventative health care should increase. On the other hand it has been found that individuals who are in a poor health status are less likely to have pap smears and mammograms and this is especially true for women who reported very low levels of self-rated health status ${ }^{35}$ and it is explained that psychological factors such as anxiety and fear could be important reasons why sicker women avoid cancer screenings. However a further study has not confirmed this result, also women with a poor health status have not had a lower uptake rate of cervical and breast cancer screening ${ }^{25}$. Variables for health status are the self-rated health status and the General Health Questionnaire (GHQ) measure of well-being using the Caseness scale with a range from 0 (least distressed) to 12 (most distressed). Reference category for self-rated health status is a self-rated health status ranging from fair to excellent. Smoking is associated with high risk health behaviours and a lower probability of using preventative health care and individuals with risk taking behaviour such as smokers will have a lower compliance with screening guidelines for regular test ${ }^{36}$. For women with non-white ethnicity barriers in form of cultural understanding and unawareness of cervical cancer risk can exist and empirical studies have shown its predictive importance and so these women should have a lower uptake rate ${ }^{37}$. Ethnicity is included as a predictor variable for uptake and there are 2 categories: white (reference category) and non-white. For getting an invitation or recall for cervical cancer screening women have to be registered with their local GP or clinic. The information about GP registration is not available, however the BHPS contains information about moved residence (mover) and for women with moved residence the chance of missing the invitation letter for the next cervical cancer screening increases. It is plausible to expect that those who move from location to location will experience disruptions to their screening access facilities ${ }^{27}$. Geographical barriers can exist for preventative care for individuals living in urban or rural areas ${ }^{38}$, because access to health care and time cost as a non-monetary component can play an important role for the uptake of medical services especially if services are free ${ }^{39}$. There are only very few studies which have investigated the effect of time costs such as travel time on uptake ${ }^{26}$ and a study which analyse differences for living in a rural or urban environment has found a lower uptake for women living in rural areas $^{40}$. However, on the other hand patients' links to the doctor could be tighter in a rural environment as compared to an urban environment $^{32}$, so the effect is unclear. There were also regional dummies for Scotland and Wales included and England was the reference category. In October 2003 there has been a change in the national policy for women in the age range between 25 and 49 for the screening interval: before this year there has been a 5 -year screening interval, after this year a 3 -year screening interval. One indicator variable will be used for the relevant age group from 25-49 after the year 2003 to check the effect of this policy change on uptake and uptake for this age group in this time period should increase.

Analytical results. Figure 1 gives the proportion of women of age 2564 who reported to have been taken part in cervical screening in a certain (wave) of the BHPS in relationship to all women of age (2564) in a certain wave of the BHPS. This figure shows a decreasing participation uptake rate from $33.2 \%$ in 1992 to $26.5 \%$ in 2008 for self-reported screening with NHS provision. These average numbers of uptake per year are consistent with a 3-5 yearly cycle of cervical screenings which are in line with the medical recommendations for the age group between 25 and 64 by NHSCSP.

Table 1 presents descriptive statistics for the variables used in our estimation for the balanced panel and the unbalanced panel to look for attrition effects. For some variables there exists a difference between the unbalanced and the balanced panel, so that attrition effects could have an influence on the estimation ${ }^{41}$. Because of this difference and to check the robustness of the results dynamic panel probit models are estimated for the unbalanced and balanced sample and a fixed effects linear regression model for the balanced panel.

Table 2 provides the dynamic random effects (RE) probit estimates with initial conditions for the unbalanced panel (UP) (column 1) and for the balanced panel (BP) (column 2) and a fixed effects (FE) linear regression model for the balanced panel (column 3). The table is based on a sample of 33,075 observations with 3,758 women for the unbalanced panel and of 11,998 observations with 857 for the balanced panel. The unbalanced dynamic random effects probit model and the linear fixed effects-model model gave similar results in comparison to the balanced panel model and in the following the discussion concentrates on the balanced panel, because these estimations are the most reliable ones.

Since we had the repeated screening uptake information for each of the individuals, it is informative to know how past screening habit affected the current screening uptake. Women who had screened one year and three years before had a higher probability to participate in the actual period and the marginal effect showed an increase in probability of 5,4\% if screened one year before and $13,0 \%$ if screened three years before (table 3 ).

There was a non-linear relationship between age and uptake and the propensity to be screened fell with rising age and in the age category 65 it was the lowest one with a decrease of $32,3 \%$ to the reference group. Living with a partner led to a higher probability for cervical cancer screening with an increase of 3.5\%. Women with small children under age 4 had a lower probability of taking part in cervical cancer screening and showed a decrease in probability of $2.5 \%$ whereas the number of children had no significant influence. For women who visited their GP last year there was a much higher probability of cervical cancer screening and the increase in uptake was $9.1 \%$. The two health status related variables, namely poor selfrated health status and subjective well-being had no significant influence. Smoking status as a possible indicator for risky health behaviour had surprisingly no influence. Also our hypothesis of a lower probability of screening for non-white women was also not confirmed. Part- or full time-employment led to an increase to an increase of $1.6 \%$ in uptake. Further socio-economic background variables such as equivalised household income, education, rural or urban living and moved residence were not significant. The change in policy after 2003 for women of age 25-49 with reducing the recommended time interval from five to three years for this age group led not to an increase in taking part in cervical cancer screening. Regional dummy variables for Scotland and Wales were not significant at the $10 \%$-significance level. Also the Mundlak terms for the average equivalised household income and the average selfrated health status showed no significance.

\section{Discussion}

Our empirical investigation showed the importance of past screening behaviour for the recent period and also analysed which socioeconomic characteristics are important for the uptake of cervical cancer screening in the actual period. For our analysis and estimation we concentrated on a balanced sample of 857 with 11,998 observations for the period from 1992 to 2008, because using a balanced panel offers econometric advantages in comparison to an unbalanced panel. One important problem of an estimation of an unbalanced 


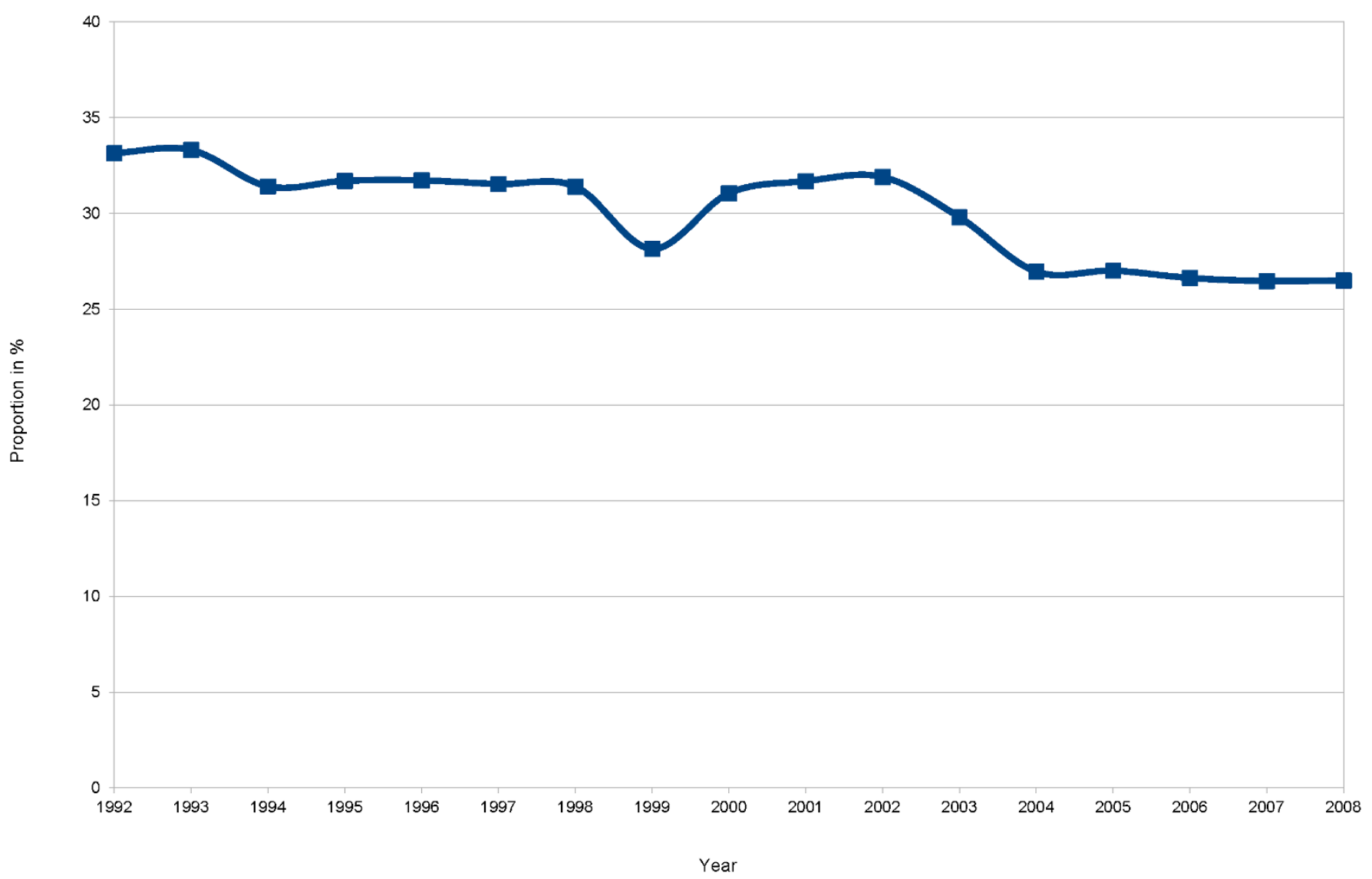

Figure 1 Self-reported cervical cancer screening with NHS provision only. Source: BHPS waves 1-18. Self-reported cervical cancer screening with NHS provision for women of age $25-64$.

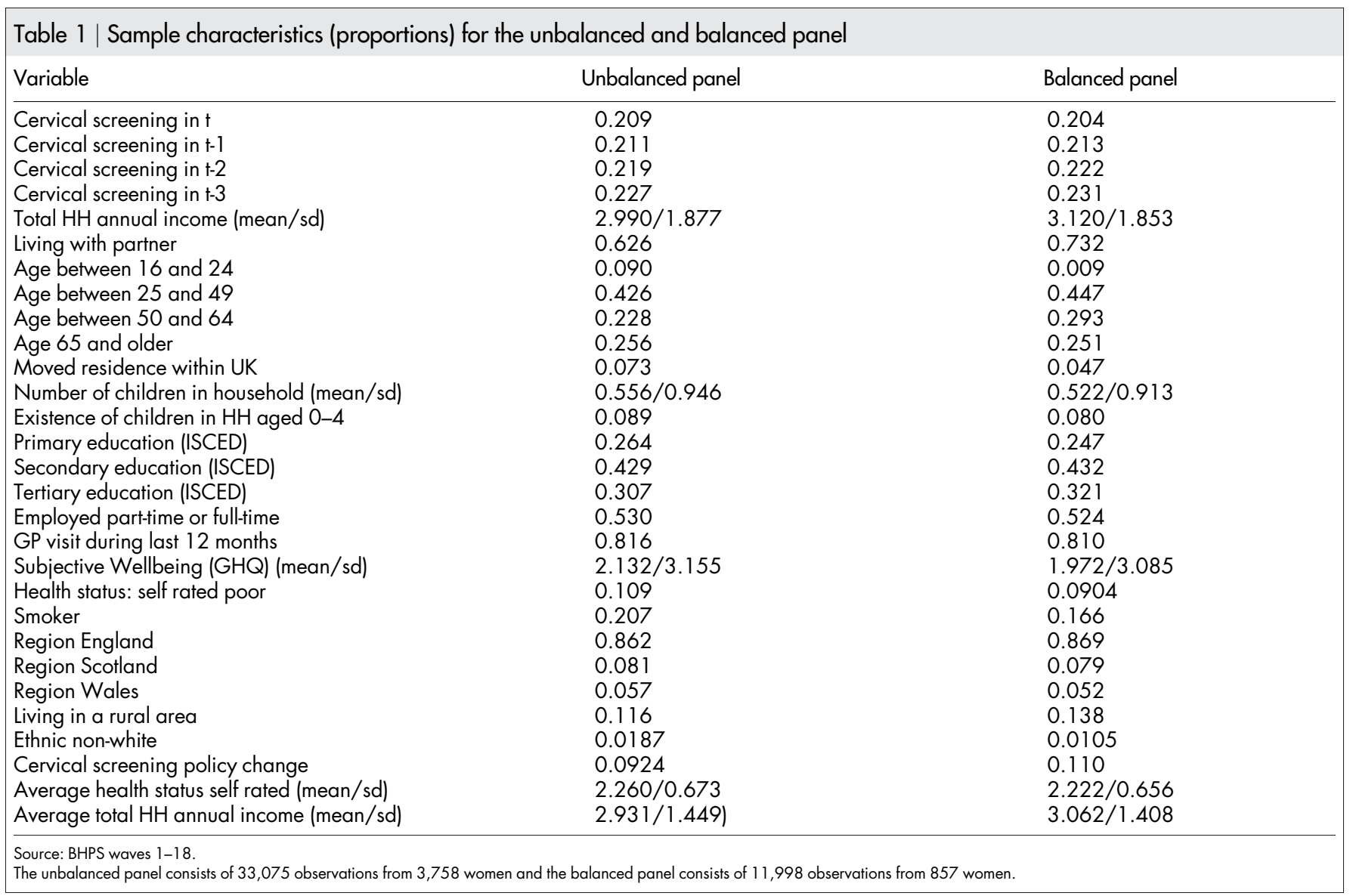




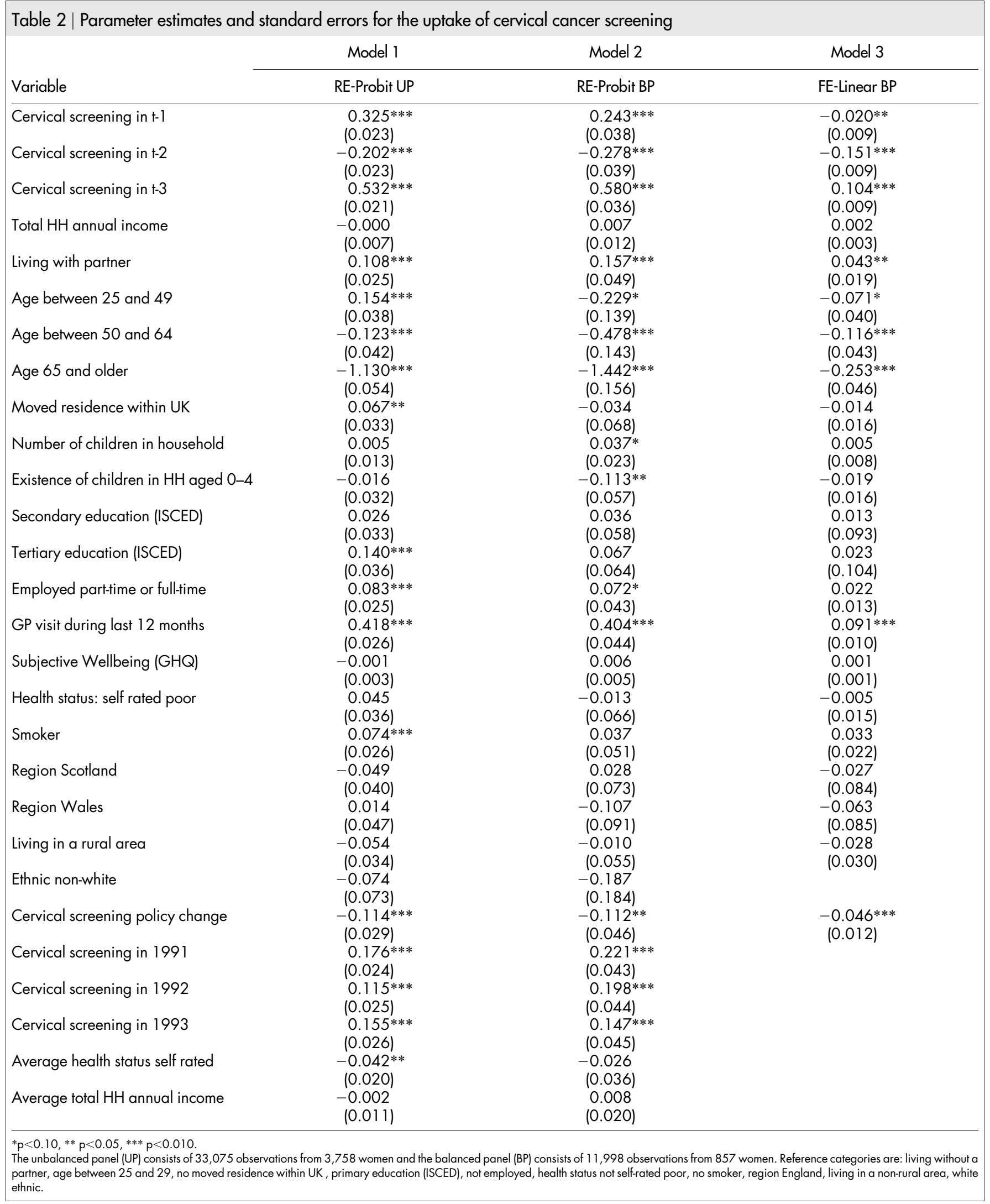

panel could be attrition bias over time and so we gave estimation of a balanced panel preference ${ }^{42}$.

In a context of an individual woman our results can be interpreted that woman who take part regularly for cervical cancer screening have a habit of using this preventative health service regularly and these results can be interpreted in the sense of state dependence ${ }^{43}$. There exists a strong positive state dependence for cervical cancer screening and this result can be explained by adherence to the medical guidelines, i.e. checking in 3-yearly intervals and after inconclusive results. The decreasing uptake with age is in accordance with the 
Table $3 \mid$ Marginal effects and standard errors for the uptake of cervical cancer screening

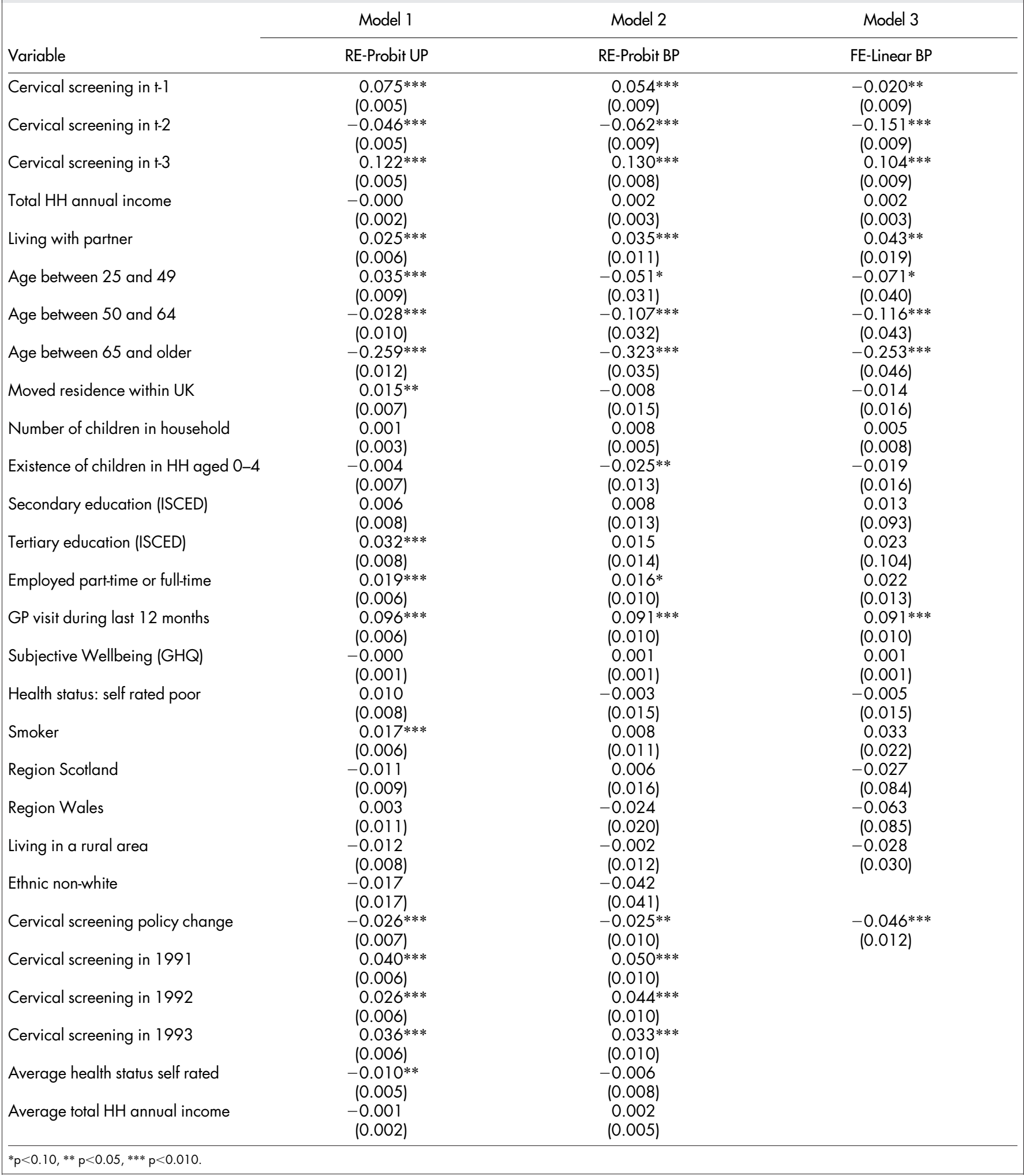

shorter pay-off period hypothesis from the human capital theory approach. The effect of age could be also explained by negative experience related to the screening procedure itself, or to updated subjective evaluations on the benefits of screening ${ }^{44}$. The positive effect of living with a partner on uptake can be interpreted to be more risk-averse if living in a partnership. The result that the existence of children under age 4 leads to a lower uptake of cervical cancer screening can be explained by the fact that only children of smaller age are a time constraint, whereas the number of children in the household or existence of older children leads not to a time constraint. Our hypothesis of a lower probability of screening for nonwhite women was not confirmed and so no cultural barrier exists for non-white women over all age group exists. The significance of a GP visit in the year before the actual wave can be explained by the fact 
that the GP plays an important role as gatekeeper and could consult in favour of doing a smear test. Health status related variables such as a higher level of distress and a poorer self-perceived health status had no influence of encouraging or avoiding cervical cancer screenings. For the socio-economic background variables only employment status had an influence whereas other socio-economic background variables such as household income, education, race, rural or urban living are not important in our analysis which is contrast to some other results. A moved residence with a higher chance of not registering for a new GP plays in our analysis no role for the uptake.

Results for cervical cancer screening in other countries such as US are not directly comparable to European countries in general, which have extensive insurance coverage and low direct payments for health services, and especially to UK with free access to most health services. As a consequence individual economic factors, especially income, play not such a role as in $\mathrm{US}^{40}$. Our results are in part in agreement with results from other studies about cervical screening. Our analysis found that previous screening, age, living with a partner and GP visit were significant in different specifications and these results are consistent with other results for England who estimated the cervical cancer screening uptake with an unbalanced panel for the first 12 waves of the BHPS until $2003^{27}$. However, there are also marked differences comparing our results with these results. Estimated coefficients for education, smoking and moved residence status were not significant in our analysis. Especially the difference in results for the variable education and smoking are remarkable, because smoking status as a possible indicator for risky health behaviour had surprisingly no influence. However, also some other studies have found no influence of smoking status on screening behaviour ${ }^{45}$. A further study from Italy used as a method a recursive probit model to analyse the uptake of cervical cancer screening in Italy. This econometric modelling was chosen to reflect the role of the GP as non-pure gate-keeper, because one or more GP visits can encourage a woman to do a smear test, however a GP visit is not essential for the provision of a smear test ${ }^{40}$. This analysis showed that GP visits led to a higher uptake of cervical screening. The institutional setting of this study is similar to the situation in UK, because cervical cancer screening can be done not only in a GP practice, but it can be also done at a community clinic.

Underuse of preventative health can also be caused by imperfect information or individuals who do not evaluate health risks correctly as for example smokers ${ }^{36}$ or who decide rationally not to take part in preventative activity or who decide to run a calculated risk ${ }^{40}$. It is sometimes argued that issues surrounding risk depend on sociocultural and life experiences of the individuals in question and the decision to take part in cancer screenings it is not only rational behaviour $^{46}$. As further non-economic reasons in not taking part fear and anxiety can especially be relevant from doing smear tests as women may fear that the screening will reveal cancer and they prefer not to know ${ }^{47,48}$. There are possible further non-economic factors influencing screening uptake and it is argued that factors such as search for reassurance, a sense of duty and herd signalling could play a role ${ }^{49}$. Also a further non-economic factor such as an awareness campaign for cancer screening ${ }^{50}$ can influence uptake rates in cancer screening. However, there is no clear evidence that awareness campaigns promote increased participation, detection and diagnosis of diseases $^{51}$.

The innovative feature of our analysis is the analysis of uptake of cervical cancer screening with a random effects panel probit model with a balanced sample. Our analysis shows the importance of past screening behaviour, decreasing participation with recommended age for cervical cancer screening, the importance of GP for cervical cancer screening and there is also no effect recognizable of shortening the screening interval from 5 to 3 years for women of age 25-49 after 2003. The change of medical guidelines by the NHSCSP has not led to an increase to an increase of uptake for this age group. A first limitation of the study is there is no information about results from previous cervical screening exams available and so it is difficult to differentiate between routine check-ups and follow-up tests which are in response to previous results. A second limitation of our study is that no information was existing about existing health beliefs such as level of trust in NHS or in GP, because it has been shown that taking part in cervical and breast cancer screening can be dependent from them ${ }^{40}$. A third limitation exists, because there was no information available about the characteristics of the primary care factors which have been shown to be associated with cervical cancer screening in England $^{52}$. These factors are variables such as the characteristics of the medical performing of the screening test, structure and organization of medical centres. Also GPs with a specialisation in the area of gynaecology and obstetrics have often a higher probability to recommend preventative treatment ${ }^{31}$ and also female physicians have a higher probability to do a pap smear ${ }^{53}$. A fourth limitation of our study comes from not using microgeographic information, because cervical cancer screening coverage was found to be higher in affluent and less deprived area in Italy ${ }^{54}$.

\section{Methods}

As dataset is the British Household Panel Survey (BHPS) used which is an annual survey of households in UK and it is a nationally representative sample of more than 5,000 households and each adult with age 16 and over is interviewed ${ }^{55}$. Data collection for this survey started in 1991 and the original individuals were also interviewed in the following years. From the interviewed individuals only female individuals were included and also women from Northern Ireland were excluded, because data collection started from wave 11 .

Our analysis used 17 years of information, from 1992 to 2008 for the unbalanced panel consisting of 3,758 women and 33,075 observations and for the balanced panel consisting of 857 women and 11,998 observations. In congruence with the cervical screening eligibility guidelines in the UK the analysis differentiate between different age groups of women: age group 16 to 24, age group 25 to 49, age group 50 to 64, age group 65 and older. Provision of cervical cancer screening for the women had to be from NHS to be included in our analysis, because there exists also the possibility of private provision in UK. The dependent variable takes the value of 1 if a cervical cancer screening was done through NHS provision and 0 if no cervical cancer screening was done. Pure private provision as well as provision provided both privately and publicly for cervical cancer screening were excluded in our analysis.

Due to the panel nature of the data on screening and the potential link between screening behaviour across time, a dynamic random effects (RE) probit model was estimated. The model is given as

$$
y_{i t}^{*}=\gamma y_{t-1}+x_{i t}^{\prime} \beta+v_{i t}, i=1,2, \ldots, N ; t=2, \ldots, T
$$

and

$$
v_{i t}=\alpha_{i}+u_{i t}
$$

and

$$
y_{i t}=\left\{\begin{array}{l}
1, \text { if }, y_{i t}^{*} \geq 0 \\
0, \text { otherwise }
\end{array}\right.
$$

where (dropping the subscripts) $y^{*}$ denotes the unobservable latent variable, $y$ is the observed outcome (i.e. participation in cervical cancer screening), $\mathrm{x}$ is a vector of time-varying and time invariant regressors that influence $y^{*}$ (i.e. the propensity to be screened), $\beta$ is the vector of coefficients associated with the regressors, $\alpha_{i}$ denotes the individual specific unobservable effect and $u_{i t}$ is a random error.

A dynamic RE specification with lagged screening histories was chosen, because the aim is not only to capture the influence of the observable characteristics, but also to explain the actual uptake behaviour by its past values and to capture state dependence. This specification is chosen, because it removes under certain assumptions the bias which is caused by the persistence of the probability of uptake. Crucial assumptions for the estimation of the dynamic random effect model are the specification of the relationship between the observed characteristics and the unobserved time-invariant individual effect and also the distributional assumption on the initial conditions.

Estimation of a balanced panel was given preference to an unbalanced panel, because estimation of unbalanced panels with ad hoc treatments of initial problems has unfavourable estimation properties ${ }^{56,57}$. One possibility for estimating such a model is the Wooldridge estimator ${ }^{42}$. For an unbiased estimation using the Wooldridge estimator with initial conditions we have to assume that unobserved past screening behaviour is uncorrelated with observed screening behaviour, i.e. that unobserved check-ups for cervical screening that happened prior to the first wave of information in the BHPS are uncorrelated with observed screening. The balanced model could also be estimated by a maximum likelihood estimator proposed by $\mathrm{Heckman}^{58}$. A comparison of the estimation properties between the Wooldridge and Heckman estimator for balanced panels of different period length has shown that the 
finite sample properties of the Wooldridge estimator are better for panels of moderate duration (more than 5 to 8 periods) than for the Heckman estimator ${ }^{59}$, so that our preferred and used estimator is the Wooldridge estimator. The specific individual random effect is modelled as Mundlak-Wooldridge specification with a normal density for the random effect and the first three terms are the initial conditions and the fourth term is the Mundlak term ${ }^{60}$ :

$$
\alpha_{i}=\delta_{1} S_{i 1}+\delta_{2} S_{i 2}+\delta_{3} S_{i 3}+\delta_{4} \overline{X_{i}^{\prime}}+e_{\alpha i}
$$

The information about screening behaviour for the first three years of observations on screening in the BHPS 1991, 1992, 1993 were taken as initial conditions into account $\left(S_{i 1}, S_{i 2}, S_{i 3},\right) . \bar{X}$ is the average of individual time-varying explanatory variables and $e_{x i}$ is the error term assumed normally distributed with zero mean and standard deviation $\sigma_{\alpha}$.

Decision to have a smear test depends also from the result of a smear test one year ago. Women with an inconclusive result from the previous year screening will be invited to screening in the actual year. The information about the results from previous screenings is missing in the BHPS. Our econometric specification uses the information about screening in the previous year and three years ago as lagged dependent variables, because such a specification considers the institutional setting with the screening recommendations (3-yearly interval) and a possible unclear smear test from the previous year.

1. NHS. Cervical Screening Programme. http://www.cancerscreening.nhs.uk/ cervical/publications/reviews-leaflets.html (25 February 2013, date last accessed).

2. Biewenga, P. et al. Prognostic model for survival in patients with early stage cervical cancer. Cancer 117, 768-776 (2011).

3. Office for National Statistics. Cancer survival in England: Patients diagnosed 2005-2009 and followed up to 2010. http://www.ons.gov.uk/ons/ dcp171780_242394.pdf (25 February 2013, date last accessed).

4. Neilson, A. \& Jones, R. K. Women's lay knowledge of cervical cancer/cervical screening: accounting for non-attendance at cervical screening clinics. J Adv Nurs 28, 571-575 (1998).

5. Office for National Statistics. Mortality statistics: deaths registered in 2009. http:// www.ons.gov.uk/ons/rel/vsobl/mortality-statistics--deaths-registered-inengland-and-wales--series-dr-/2009/mortality-statistics-deaths-registered-in2009.pdf (25 February 2013, date last accessed).

6. Quinn, M., Babb, P., Jones, J. \& Allen, E. Effect of screening on incidence of and mortality from cancer of cervix in England: evaluation based on routinely collected statistics. BMJ 318, 904-908 (1999).

7. Austoker, J. Cancer prevention in primary care. Screening for cervical cancer. BMJ 309, 241-248 (1994)

8. NHS The Health and Social Care Information Centre. Cervical Screening Programme 2010-11. http://www.cancerscreening.nhs.uk/cervical/cervicalstatistics-bulletin-2010-11.pdf (25 February 2013, date last accessed).

9. Herbert, A., Holdsworth, G. \& Kubba, A. A. Cervical screening: why young women should be encouraged to be screened. J Fam Plann Reprod Health Care 34, 21-25 (2008).

10. Sasieni, P., Castanon, A. \& Cuzick, J. Effectiveness of cervical screening with age: population based case-control study of prospectively recorded data. BMJ 339, b2968 (2009).

11. Fiander, A. N. Cervical screening in young women aged 20-24 years. J Fam Plann Reprod Health Care 34, 19 (2008).

12. Rieck, G. C., Tristram, A., Hauke, A., Fielder, H. \& Fiander, A. N. Cervical screening in 20-24-year olds. J Med Screen 13, 64-71 (2006).

13. Howe, A., Owen-Smith, V. \& Richardson, J. Health authority cervical screening recall policies and time since last smear: a retrospective cohort analysis in the north west England. J Med Screen 10, 184-188 (2003).

14. National Health Service. in: Patnick J. (ed.) Building on experience: Cervical screening programme (NHS, London, 2002).

15. Lancuck, L., Patnick, J. \& Vessey, M. A cohort effect in cervical screening coverage? J Med Screen 15, 27-29 (2008).

16. The Health and Social Care Information Centre. Cervical screening programme England 2010-11. (2011).

17. NHS Cervical Screening Programme. Annual review 2011. (25 February 2013, date last accessed).

18. Grossman, M. On the Concept of Health Capital and the Demand for Health. JPE 80, 223-255 (1972).

19. Kenkel, D. S. Prevention. in: Culyer, A. J., Newhouse, J. P. (eds.) Handbook of Health Economics. Vol. 1, Chpt. 31, 1675-1720 (Elsevier, North Holland, 2000).

20. Ehrlich, I. \& Becker, G. S. Market Insurance, Self-Insurance, and Self-Protection. JPE 80, 623-648 (1972).

21. Selden, T. M. Uncertainty and health care spending by the poor: the health capital model revisited. J Health Econ 12, 109-115 (1993).

22. Zweifel, P., Breyer, F. \& Kifmann, M. Health economics (Springer, Berlin, 2009).

23. Cropper, M. L. Health, Investment in Health, and Occupational Choice. JPE 85, 1273-1294 (1977).

24. Jepson, R. et al. The determinants of screening uptake and interventions for increasing uptake: a systematic review. Health Technol Assess 4, 1-133 (2000).
25. Walter, L. C., Lindquist, K. \& Covinsky, K. E. Relationship between health status and use of screening mammography and Papanicolaou smears among women older than 70 years of age. Ann Intern Med 140, 681-688 (2004).

26. Lairson, D. R., Chan, W. \& Newmark, G. R. Determinants of the demand for breast cancer screening among women veterans in the United States. Soc Sci Med 61, 1608-1617 (2005).

27. Sabates, R. \& Feinstein, L. The role of education in the uptake of preventative health care: the case of cervical screening in Britain. Soc Sci Med 62, 2998-3010 (2006).

28. Rodvall, Y., Kemetli, L., Tishelman, C. \& Tornberg, S. Factors related to participation in a cervical cancer screening programme in urban Sweden. Eur J Cancer Prev 14, 459-466 (2005).

29. Lagerlund, M. et al. Sociodemographic predictors of non-attendance at invitational mammography screening - a population-based register study (Sweden). Cancer Causes Control 13, 73-82 (2002).

30. Majeed, F. A. et al. Using patient and general practice characteristics to explain variations in cervical smear uptake rates. BMJ 308, 1272-1276 (1994).

31. Kenkel, D. S. The Demand for Preventative Medical Care. Applied Economics 26, 313-325 (1994).

32. Challier, B., Meslans, Y. \& Viel, J. F. Deprived areas and attendance to screening of cervix uteri cancer in a French region. Cancer Causes Control 11, 157-162 (2000).

33. Jenkins, S. P. The British Household Panel Survey and its income data. ISER Working Paper Series, No. 2010-33 (Colchester, 2010).

34. Scott, A. Economics of general practice. Handbook of Health Economics, Vol. 1, 1175-1200 (Elsevier 2000).

35. Wu, S. Sickness and preventive medical behavior. J Health Econ 22, 675-689 (2003).

36. Viscusi, W. K. Do Smokers Underestimate Risks? JPE 98, 1253-1269 (1990).

37. Moser, K., Patnick, J. \& Beral, V. Inequalities in reported use of breast and cervical screening in Great Britain: analysis of cross sectional survey data. BMJ 338, b2025 (2009).

38. Great Britain. Commission for Rural Communities. Darzi Analysis: Access To, and Quality Of, Health Care in Rural England (Commission for Rural Communities, 2008).

39. Acton, J. P. Nonmonetary Factors in the Demand for Medical Services: Some Empirical Evidence. JPE 83, 595-614 (1975).

40. Carrieri, V. \& Bilger, M. Preventive care: underused even when free. Is there something else at work? Applied Economics 45, 239-253 (2013).

41. Verbeek, M. \& Nijman, T. Testing for Selectivity Bias in Panel Data Models. International Economic Review 33, 681-703 (1992).

42. Wooldridge, J. M. Simple solutions to the initial conditions problem in dynamic, nonlinear panel data models with unobserved heterogeneity. J Appl Econ $\mathbf{2 0}$, 39-54 (2005).

43. Rauscher, G. H., Hawley, S. T. \& Earp, J. A. Baseline predictors of initiation vs. maintenance of regular mammography use among rural women. Prev Med 40, $822-830$ (2005).

44. Biro, A. An analysis of mammography decisions with a focus on education differences (University of York, Health, Econometrics and Data Group (HEDG) WP 12/11 2012).

45. Clark, M. A., Rakowski, W. \& Ehrich, B. Breast and cervical cancer screening: associations with personal, spouse's, and combined smoking status. Cancer Epidemiol Biomarkers Prev 9, 513-516 (2000).

46. Vahabi, M. \& Gastaldo, D. Rational choice(s)? Rethinking decision-making on breast cancer risk and screening mammography. Nurs Inq 10, 245-256 (2003).

47. Carter, J., Park, E. R., Moadel, A., Cleary, S. D. \& Morgan, C. Cancer knowledge, attitudes, beliefs, and practices (KABP) of disadvantaged women in the South Bronx. J Cancer Educ 17, 142-149 (2002).

48. Meystre-Agustoni, G., Paccaud, F., Jeannin, A. \& Dubois-Arber, F. Anxiety in a cohort of Swiss women participating in a mammographic screening programme. J Med Screen 8, 213-219 (2001).

49. Whynes, D. K., Philips, Z. \& Avis, M. Why do women participate in the English cervical cancer screening programme? J Health Econ 26, 306-325 (2007).

50. Belkar, R., Fiebig, D. G., Haas, M. \& Viney, R. Why worry about awareness in choice problems? Econometric analysis of screening for cervical cancer. Health Econ 15, 33-47 (2006).

51. Jacobsen, G. D. \& Jacobsen, K. H. Health awareness campaigns and diagnosis rates: evidence from National Breast Cancer Awareness Month. J Health Econ 30, 55-61 (2011).

52. Bang, J. Y., Yadegarfar, G., Soljak, M. \& Majeed, A. Primary care factors associated with cervical screening coverage in England. J Public Health (Oxf), 1-7 (2012).

53. Lurie, N. et al. Preventive care for women. Does the sex of the physician matter? $N$ Engl J Med 329, 478-482 (1993).

54. Baker, D. \& Middleton, E. Cervical screening and health inequality in England in the 1990s. J Epidemiol Community Health 57, 417-423 (2003).

55. Brice, J., Buck, N. \& Prentice-Lane, E. British Household Panel Survey User Manual. Volume A: Introduction, Technical Report and Appendices (Colchester, 2010).

56. Honore, B. Nonlinear models with panel data. Portugese Economic Journal $\mathbf{1}$, 163-179 (2002).

57. Wooldridge, J. M. Correlated random effects models with unbalanced panels (Michigan State University, Department of Economics, 2010). 
58. Heckman, J. Statistical models for discrete panel data. in: Manski, C. F., McFadden, D. (eds.) Structural Analysis of Discrete Data with Econometric Applications, Chpt. 3, 114-178 (MIT Press, Cambridge, 1981).

59. Akay, A. Finite-sample comparison of alternative methods for estimating dynamic panel data models. J Appl Econ, doi: 10.1002/jae.1254 (2011)

60. Mundlak, Y. On the Poooling of Time Series and Cross Section Data. Econometrica 46, 69-85 (1978).

\section{Acknowledgements}

This research used the SPECTRE High Performance Computing Facility at the University of Leicester. The research was funded by and took place at the National Institute for Health Research (NIHR) Collaboration for Leadership in Applied Health Research and Care based at Leicester. The views expressed are those of the author(s) and not necessarily those of the NHS, the NIHR or the Department of Health.

\section{Author contributions}

A.L. and A.K. performed statistical analyses and all 3 authors discussed and contributed to the text of the manuscript. All three authors reviewed the manuscript.

\section{Additional information}

Competing financial interests: The authors declare no competing financial interests.

How to cite this article: Labeit, A., Peinemann, F. \& Kedir, A. Cervical Cancer Screening Service Utilisation in UK. Sci. Rep. 3, 2362; DOI:10.1038/srep02362 (2013).

(c) (1) () $\Theta$ This work is licensed under a Creative Commons Attribution-

(ay No No NonCommercial-NoDerivs 3.0 Unported license. To view a copy of this license, visit http://creativecommons.org/licenses/by-nc-nd/3.0 